\title{
Discussion on the Comparison in Costumes between China's Traditional Meticulous Painting of the Figures of Ladies and Ukiyoe Beauty Painting
}

\author{
Xiaosha Wang \\ Academy of fine arts, China West Normal University, Nanchong 637002, Sichuan, China. \\ 601953917@qq.com
}

\begin{abstract}
The creation of women's images is called as the "painting of the figures of ladies" in Chinese paintings, and it is called as "beautiful paintings" in Japanese paintings. Japanese Kayoed beauty painting originates from painting of the figures of ladies in China's Tang Dynasty, and is constantly developing under the influence of China's traditional meticulous painting of the figures of ladies. This paper aims at comparing costumes between China's traditional meticulous painting of the figures of ladies and Kayoed beauty painting on the basis of the collection and collation of existing data, studies, analyzes, and discusses the similarities and differences between the two, and combines practical experience with theoretical knowledge to discuss it.
\end{abstract}

Keywords: China's traditional meticulous painting of the figures of ladies, kayoed beauty painting, costume, influence.

\section{论中国传统工笔仕女画和浮世绘美人画在服饰上的比较}

\section{王潇莎}

西华师范大学 美术学院, 四川 南充 637002

摘要: 女性形象的创作在中国画中被称为 “仕女画”，在日本画中被称作 "美人画 "。日本 浮世绘美人画胎息于中国唐代仕女画，在中国传统工笔仕女画的影响下不断发展。本文旨在 对现有资料收集整理的基础上, 对中国传统工笔仕女画及日本浮世绘美人画中的服饰做比较, 研究、分析和讨论两者的异同，并结合实践经验和理论知识作一论述。

\section{关键词：中国传统工笔仕女画 浮士绘美人画 服饰 影响}

\section{1. 前言}

女性在绘画作品中作为表现对象，具有悠久的历史。以女性为绘画题材的创作在传统中国人 物画中被称为 “仕女画” ，在日本人物画中被称作 “美人画”。追溯中日两国的文化交流源 远流长, 日本艺术与中国艺术血脉相融, 日本的绘画从飞鸟时代到江户时代历经的一千二百 多年发展过程中无不在学习中国的绘画, 并以不同的形式反映着中国古代文化思想, 与中国 古代文化有着千丝万缕的联系和密不可分的渊源关系。日本浮世绘美人画在发展变化过程中， 始终受到中国传统工笔仕女画的影响, 我们透过其媚艳浮华的外表下, 仍可清晰的探到它在 绘画中的服饰亦深受中国传统工笔仕女绘画艺术影响的痕迹。并以各自独具民族特点的艺术 形式，给世人展现和认识东方女性的不同美。

\section{2. 发髺}

仕女的发型是随着时代的发展而变化的。中国传统工笔仕女画中大致有高䯽、灵蛇䯽、九㗒 仙䯽、螺䯽等等, 最常见的是从汉代开始盛行于唐、五代的高䯽。高䯽, 总发也, 挽发而束 之于顶, 特别是唐代妇女的发型, 直接影响到五代和北宋末年, 它既是《䙃花仕女图》中贵 妇的代表发型, 又在《韩熙载夜宴图》中展现不同的美。它的特点是厚重高大, 利用自己收 
集或别人剪下的头发添加在自己的头发中, 或以之做成各种假髧来装戴。而浮世绘美人画中 美人的发䯽几乎都是从中国的高䯽演变而来的, 将全部的头发高高束在头顶上, 露出光亮的 前额及后颈，称为岛田䯽。

\section{3. 头饰}

中国传统工笔仕女画的头饰缤纷复杂，让人目不暇接。画家根据古诗《羽林郎》“头上蓝田 玉” ; 曹植《洛神赋》 “载金翠之首饰” ; 白居易《长恨歌》 “云髸花颜金步摇” 等等这些 描写古代妇女头饰的诗句作为工笔仕女画头饰的依据。譬如 “头上蓝田玉” 就是指周昉《纨 扇仕女图》中仕女头上所戴的用玉做成的头饰; “金步摇” 是五代阮郜的《纨扇仕女图》中 仕女的头饰。各个朝代的发饰虽因当时不同的时尚而各异, 但总的来说都离不开梳、钗、笄 等束发工具。于是首饰艺人就在这几种束发工具上雕刻纹饰，或镶嵌金银珠宝，极尽奢华。 浮世绘美人画美人的头饰相对来说就显得极为简单, 基本上就是原始牙梳、笄, 钗等束发工 具, 少有镶嵌及雕刻装饰。类似于中国五代时的高䯽与银钗牙梳相配, 但浮世绘美人画中和 服美人头上的钗和笄造型比之更纤长, 且往往以数根从两端分别插入发中, 那长长的䈂呈放 射状形成对称, 别具一种形式美。她们有时还会戴角隐, 也就是我们说的蒙头的帽子, 其实 是一种美女们游山玩水时戴的防尘帽。一般从前额顶分两边向脑后缠绕, 在头顶打结, 戴在 高高的岛田式发䯽上。在鸟居清长的《春之野游》中, 那头戴角隐, 发插笄的美人正向我们 展示出日本民族那独特的头饰美。

\section{4. 服式}

中国历代妇女的服装式样众多, 变化颇大。即使是某一个相同时期内, 服装式样也经常反复, 如唐代上衣的袖子就经过了宽一窄一宽的变化。尽管服式千变万化, 然而至明清, 中国传统 工笔仕女画大都采用了唐、五代的妇女服式。顾恺之《女史筬图》中每个仕女的上衣皆为广 袖, 并流传下来; 到周昉的《䙃花仕女图》中演变为宽袖; 再到五代顾闳中《韩熙载夜宴图》 中仕女又着窄袖, 反反复复, 光袖子的宽窄变化就体现出不同时代中国传统工笔仕女画的不 同风格。总的来说, 除上衣外, 古代仕女衣着通常有以下几种, 即领边、衬衣、大带、裙腰、 正面小带、侧面小带、腰裙边及土裙。其中, 腰裙是在唐后出现的。从《穊花仕女图》中我 们可以看到唐代仕女不着腰裙, 而是将土裙直接系到胸部, 体形就显得格外修长, 里面不着 内衣，仅仅以轻纱蔽体。“绮罗丝缕见肌肤” 的句子形容的就是这种装束。大带又名风带， 是仕女衣饰中最主要的带子。“吴带当风” 就是表达的此类风带的飘逸舒卷, 它是增强仕女 动态, 表现美感和神采的有效手段。此外, 还有一根用双带打成蝴蝶结样式的花结系在腰上, 作为拦裙带子的正面小带, 它在仕女服饰中同样为表现飘逸感不可或缺, 也占有很重要的地 位。此外, 仕女脚下穿的是用凤头装饰缝在前端的鞋, 通称 “凤头鞋”。由于中国古代有缠 足的习惯, 既不健康又不美观, 因此历代画家少有画脚的。只有在张萱《捣练图》等唐、五 代的工笔仕女画中才会看到在土裙下稍露出的那一点凤头。

浮世绘美人画中美人身着和服, 是日本的传统民族服装, 但追究其根源, 它源自中国唐代的 长袍。是日本奈良时代从中国的江浙一带 “移植” 过来, 被称为唐风贵族服。到平安时代, 也就是日本的 “国风时代” ，在全盘消化唐文化后，以毕业生之态堂堂登上了历史的舞台。 他们施以一些改造, 譬如加长袖子, 把衣服的幅度变宽。但为给人以美感, 宽大的和服穿时 需要紧紧贴在身上, 有意识的显示出人的线条美。基础和服是一种齐踝长的有宽大的长袖和 $\mathrm{v}$ 形领的衣袍。整件衣服既无衣扣又无绊带, 而是在胸前将左襟盖在右襟上, 然后在腰部用 腰带或和服的带束穿。“最初的和服腰带窄而细, 打结在腰前。桃山时代后, 日本女子不再 穿裙子, 腰带露在外面, 看起来不顺眼, 而且破坏体形美。后来受到中国文化的影响, 开始 系筒装腰带, 并改在前方打结”。 
与和服相配的是草屐和木履。草屐呈椭圆足形, 使用革、草、布制作而成。发明于古代中国, 在《后汉书》中已有记载, 日本平安时代出版的《西宫记》中也出现过草履两个字。清长的

《春之野游》中的黑衣美人脚上正是穿的草履。由于日本女人不束脚, 浮世绘美人画面多有 表现光滑的小脚或着草屐、木履，表现户外美人穿着草履漫步的情景，另外还热衷于表现囯 室风情中, 美人光着细白柔滑的小脚 Y的场景。在这种特殊的民族服装包裹下露出来两头, 既满足了浮世大众审美要求, 又使日本民族的含蓄美和诱惑美体现得淋漓尽致。

\section{5. 纹式}

中国传统工笔仕女画和浮世绘美人画中，人物服饰上都要画上一些图案和花纹，借以色彩突 出人物的形象, 体现丰富的画面效果, 增强观赏性和装饰性。中国传统工笔仕女画中的图案 纹样随着历史的发展而不断变化，各朝代都因服装不同而图案纹样各异，标志着不同的时代 特征。长沙汉墓的《龙风人物帛画》中贵妇衣服上的图案，“云纹”、“回纹” 等纹样异常 精美, 可算是最早的仕女衣饰绘画图案。而在张萱、周昉画中，流行于唐代的 “唐草” 和 “番 莲” , 汉代却没有, 足以说明汉、唐两代妇女衣服纹式有着明显不同的特点。五代继承汉代 的纹样较少, 而延续了唐代的纹样; 宋、元、明、清的图案纹样却直接受五代的影响。中国 传统工笔仕女画的图案纹样虽然很多, 但用在仕女服饰上一般有九种: 方格式; 蜂窝式（也 称龟背式）; 古钱式（也可称套圈式）; 云头式; 由唐草演变而来的拐如意式; 菱形式; 波 纹式和散点式。其中, 波纹式多用于仕女土裙底部, 而散点式 (一切不连属的图案花纹按对 祄排列组合而成的都称为散点式）以动物纹、云鹤纹、各种花纹最常见。如《簪花仕女图》 上最左边的贵妇带上的云鹤纹样, 土裙上的番莲花样; 唐寅《孟蜀宫妓图》中仕女衣领及土 裙上的拐如意式等等都显得异常精美，突出了衣服的华丽质感。

日本江户时代正好开始大量流行各种纹样, 为浮世绘美人画的美人服饰纹样创作提供了丰富 参照。美人和服及其带的图案纹样既有全部一体的循环纹样，也有不循环纹样经排列组合而 成的模样。日本纹样的原型大多来自自然界的花鸟风月或生活中的各种道具。通常包括四大 类: 植物纹样（梅、樱、藤、菊等）; 动物纹样（龙、凤、鱼、鸟、虫等）; 器物纹样（扇 子、团扇、茶道具等）；几何纹样（麻叶、网眼、龟甲等）。此外, 在纹样的风格中, 还喜 用受中国传统思想影响所产生的带有吉祥含义的各种题材吉祥纹样, 如松、竹、梅等植物纹 样; 鹤、龟、凤凰等动物纹样以及各种宝物纹样等等。当时以卷草式样构成的唐草纹样也盛 为流行, 可分为葡萄唐草、菊唐草、牡丹唐草等, 明显带有中国唐代风格。另外, 还有一种 将经向的缟纹样与纬向的缟纹样组合起来形成的最为普通的格子纹样。喜多川歌麻吕《木琴 与三弦之合奏》中, 左边的美人和服上即为这种格子纹样; 前面距离观者最近, 趾坐着的美 人身上和服不仅带有扇形纹样, 黄色的葡萄唐草纹样还点缀着上方, 下方却装饰着飘动的羽 毛纹样; 靠右身着普通直立条形纹样和服的人面前, 木琴上用的是中国的拐如意配花饰的混 合纹样; 而最右边站立的美人手捧的带上纹式正是仕女画纹样中常见的六角形蜂窝式纹样, 里面配以菊花纹样点缀, 和服下方流动着梅花纹样……整个画面的各种美丽纹样让人目不暇 接，极具观赏性和装饰性。

一个民族的特性是一个民族在特定生存地域和生活环境中孕育出来, 它是无形却无处不在的。 中国传统工笔仕女画服饰崇尚表现含蓄柔美、矝持的内在美风格, 画中的仕女形象传达出来 的精神给人的感觉就是安静、温柔、宁顺, 有含蓄逸雅之貌; 体态平缓、神情安详平和, 让 人轻松随意, 没有紧张感。这种风格的形成与传统中国古代封建礼教思想对妇女产生长期的 束缚有很大关系。而浮世绘美人画中的服饰与中国传统工笔仕女画的服饰既有共性又在双方 不同的社会历史背景、民族传统、文化习俗所形成的审美观念的不同下存在自己独特的个性， 在融合外来艺术与本民族艺术的基础上移植、吸收、消化、演绎，从而展现自己别具一格的 形式美。 


\section{References}

[1]. He Xin. Art analysis and aesthetic debate [M]. Beijing: juju press, 2001.9, 78-82.

[2]. Qi Zahra. The influence of ancient Chinese aesthetic culture on Japanese aesthetic thoughts. Journal of three gorges university [J]. Journal of three gorges university press, 2001, 67-68.

[3]. Lin Mu. Painting style of ancient Chinese characters [M]. Chongqing: Chongqing press, 1995, 55-56.

[4]. Wang Chosen. Leading to life [M]. Beijing: writer's publishing house, 1984, 42-45. 